\title{
Fatigue Property of Additively Manufactured Ti-6Al-4V under Nonproportional Multiaxial Loading
}

Yuya Kimura' ${ }^{1}$, Fumio Ogawa ${ }^{2}$ and Takamoto Itoh ${ }^{3^{*}}$ (D)

\begin{abstract}
The low cycle fatigue strength properties of the additively manufactured Ti-6Al-4V alloy are experimentally investigated under proportional and nonproportional multiaxial loading. The fatigue tests were conducted using hollow cylinder specimens with and without heat treatments, at room temperature in air. Two fatigue tests were conducted: one for proportional loading and one for nonproportional loading. The proportional loading was represented by a push-pull strain path (PP) and the nonproportional loading by a circle strain path (CI). The failure lives of the additively manufactured specimens were clearly reduced drastically by internal voids and defects. However, the sizes of the defects were measured, and the defects were found not to cause a reduction in fatigue strength above a critical size. The fracture surface was observed using scanning electron microscopy to investigate the fracture mechanisms of the additively manufactured specimens under the two types of strain paths. Different fracture patterns were recognized for each strain paths; however, both showed retention of the crack propagation, despite the presence of numerous defects, probably because of the interaction of the defects. The crack propagation properties of the materials with numerous defects under nonproportional multiaxial loading were clarified to increase the reliability of the additively manufactured components.
\end{abstract}

Keywords: Additive manufacturing, Ti-6Al-4V, Low cycle fatigue, Multiaxial stress, Nonproportional loading, Internal defect

\section{Introduction}

Additive manufacturing (AM) has enabled the fabrication of complex geometrical parts, reducing weight and shortening the processing time as a result of the creation of subsequent thin cross-sections of a component. This represents one of the innovative fabrication technologies [1-3]. However, AM has many process parameters, and its process control is extremely problematic. Furthermore, defects and residual stresses arise because of thermal expansion or thermal contraction in the manufacturing process [2-8]. Therefore, AM is often

\footnotetext{
${ }^{*}$ Correspondence: itohtaka@fc.ritsumei.ac.jp

${ }^{3}$ Department of Mechanical Engineering, Ritsumeikan University,

Shiga 5258577, Japan

Full list of author information is available at the end of the article
}

considered undesirable because the strength reliability of the AM parts is inferior to that of traditional manufacturing technologies, such as casting, forging, and rolling in general $[9,10]$. Accordingly, to widen the applicability of AM parts, the fatigue strength properties of additively manufactured components need to be understood accurately. Lee et al. [11] reported the fatigue testing of SUS304L steel fabricated via AM. They reported that the fatigue life was sensitive to the surface roughness and that the sensitivity was magnified at lower stress levels. Sheridan performed fatigue testing of an AM-processed alloy 718 and explored the relationship between the pore size and the stress levels. The scatter in the related $\mathrm{S}-\mathrm{N}$ curves was due to the interaction between the applied stress and the pore size [12]. Generally, the fatigue life of AM parts is sensitive to the defect size and distribution, 
and it is important to identify and characterize the effect of defects on fatigue failure to properly evaluate fatigue life [13-19].

The titanium alloy $\mathrm{Ti}-6 \mathrm{Al}-4 \mathrm{~V}$ is currently utilized, mostly in the aeronautical and medical fields, because it has the properties of high strength, excellent thermal and corrosion resistance, and biocompatibility. However, this material is expensive, and its machinability is poor. From the above, Ti- $6 \mathrm{Al}-4 \mathrm{~V}$ is considered a good material for AM [20]. Uniaxial high cycle fatigue tests for AM Ti-6Al$4 \mathrm{~V}$ have been analyzed widely; however, research on the low cycle fatigue strength under nonproportional multiaxial loading in which the principal direction of stress or strain changes in a cycle has been limited.

Pegues et al. [21] investigated the effect of the feedstock of the powder, manufacturing, and post-process on AM Ti-6Al-4V materials. AM Ti-6Al-4V materials without any further surface and/or thermal post-processing treatment exhibited significantly shorter failure lives than wrought materials because of microstructural differences, defects, residual stresses, and surface roughness. Component level fatigue tests were also performed. Molaei et al. [22] performed uniaxial and multiaxial fatigue tests of notched AM materials, and clarified the effect of stress concentration on the failure lives of AM materials. The cracking behaviors of AM materials are largely different from those of wrought materials. However, few tension torsion fatigue tests have been conducted under nonproportional multiaxial conditions that have focused on internal defects on the failure lives of AM materials.

In this study, low cycle fatigue tests under nonproportional multiaxial loading were conducted using an additively manufactured specimen. Additionally, the fracture mechanism of the AM components with defects was investigated by observing the fracture surface. Then, factors affecting the decrease in fatigue strength were discussed, focusing on internal defects, which have rarely been considered in previous studies [23].

\section{Laser Powder Bed Fusion}

Laser powder bed fusion (L-PBF) is the most-employed technique for the fabrication of AM components [24]. The steps of the fabrication technique are shown schematically in Figure 1, and the manufacturing processes are as follows: (1) a layer of powdered material is applied to the building platform; (2) the powdered material is solidified into a cross-section of a 3D model using a laser; (3) the building platform is lowered, and the next layer of powder is applied; (4) the process is repeated until the fabrication of the part is complete; and (5) the part is removed from the unused powder.

L-PBF can be used to economically fabricate ideal parts with complex geometries with a rapid manufacturing-cycle design, as its advantages. However, the disadvantages of this process are that the components fabricated by L-PBF have voids, residual stresses, and surface roughness resulting from the influences of different process parameters. To improve these factors, hot isostatic pressing (HIP) and sandpapering can be performed to remove voids and surface roughness, respectively. Thus, the fatigue strength of AM components can be improved.

\section{Low Cycle Fatigue Tests}

\subsection{Testing Machine}

Figures 2 and 3 show a schematic view and a photograph of the electrical servo-controlled tension torsion fatigue testing machine, respectively. The testing machine is equipped with two types of cylinders for axial and torsion loading, and it enables the generation of nonproportional loading. The maximum axial load is $50 \mathrm{kN}$ and the maximum torque is $500 \mathrm{~N} \cdot \mathrm{m}$. The load cell was equipped for load measurement, and the extensometer, which was equipped with an eddy current sensor, was used to detect the axial and shear strains simultaneously. Figure 4 shows a schematic view of the extensometer attached to the specimen.

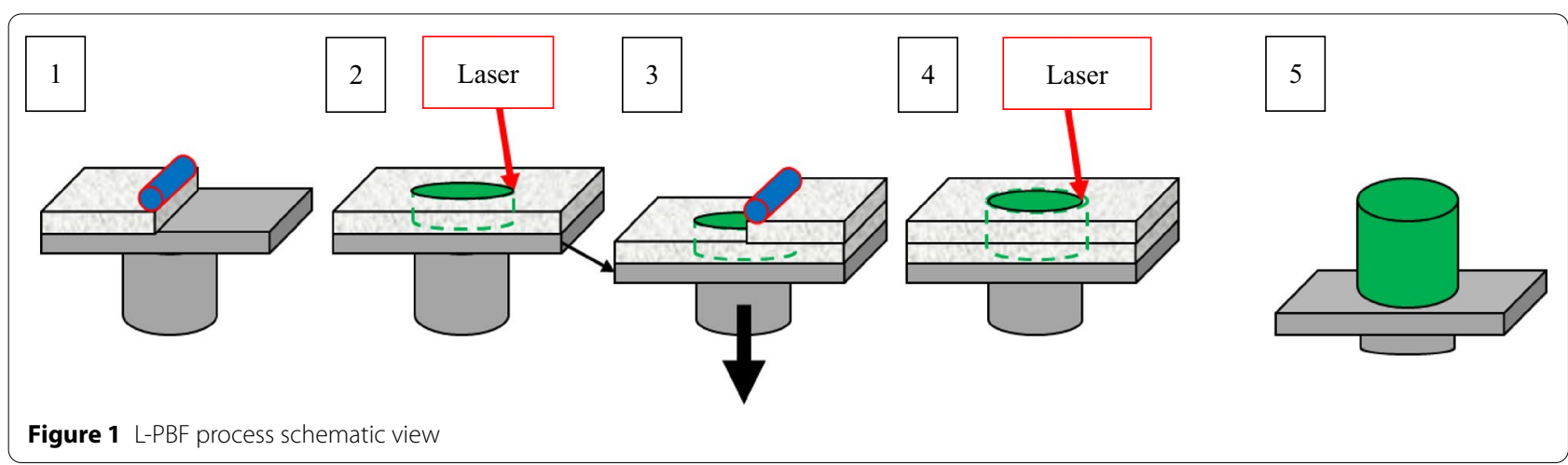




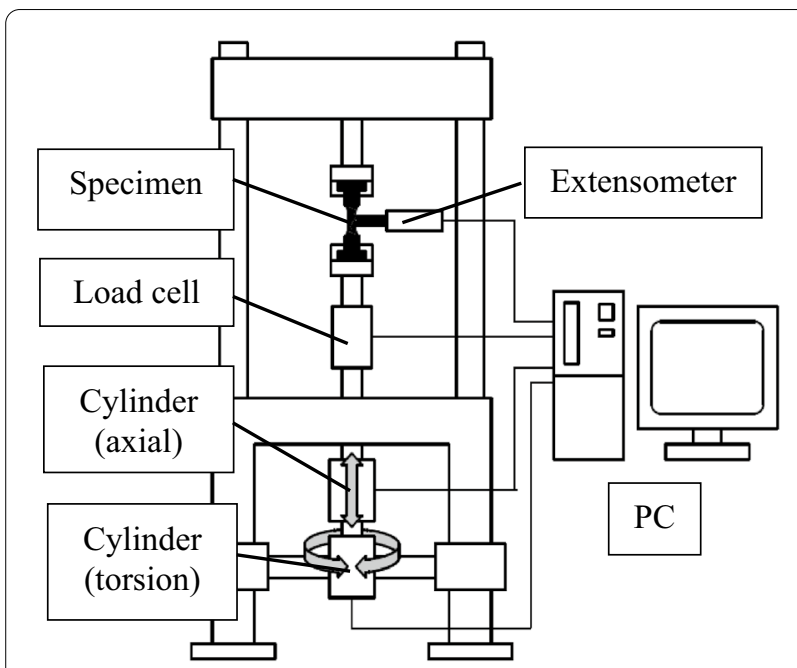

Figure 2 Schematic view of the fatigue testing machine

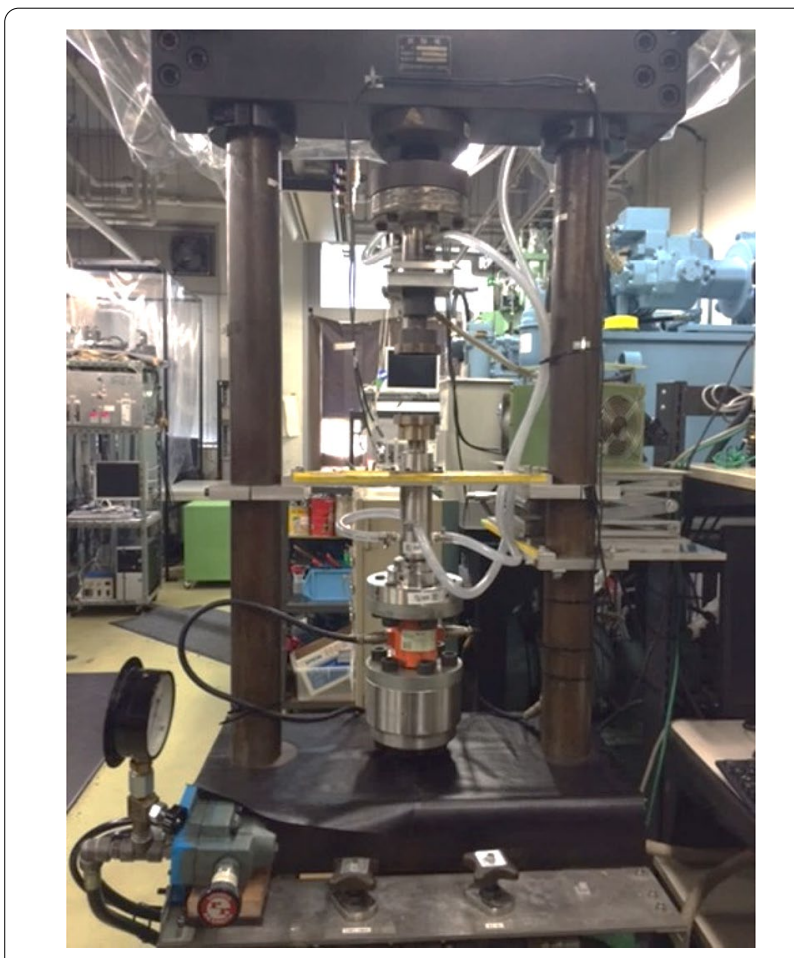

Figure 3 Photographic image of the fatigue testing machine

\subsection{Material and Specimen}

The material tested was titanium alloy Ti-6Al-4V. Figure 5 shows the shape and dimensions with no machining process and the resultant hollow cylinder specimen, which has a $9 \mathrm{~mm}$ inner diameter, an $11 \mathrm{~mm}$ outer diameter, and a $12 \mathrm{~mm}$ parallel part. The two types of specimens were "with heat treatment" (HT) and "without heat

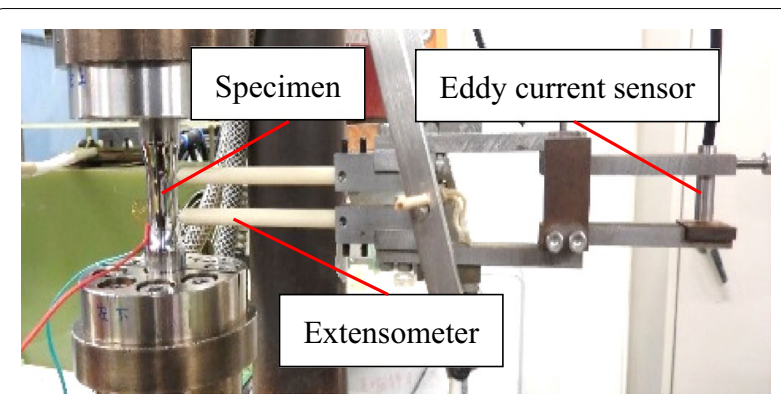

Figure 4 State of lever-type extensometer during fatigue test

treatment" (NHT) to remove the residual stresses. The layer was laminated perpendicularly to the longitudinal direction of the specimen. The specimens were polished with an aluminum powder solution (particle size $1 \mu \mathrm{m}$ ) on the external surface and with a \#2000-grit sandpaper on the internal surface to avoid the influence of surface roughness on the fatigue life. The parallel parts of the specimens had numerous defects; however, the number of defects differed for each of them.

\subsection{Test Conditions}

A testing machine that could perform tensile and torsion tests was used to apply both proportional and nonproportional loading paths to the specimens. The proportional loading path was represented by PP, whereas the nonproportional loading path was represented by $\mathrm{CI}$, in which the axial and shear strains were 90 degrees out-of-phase. In the CI, the intensity of the von Mises' equivalent strain was constant, while the direction of the principal strain changed during the cycle. The axial and shear strains were measured using an extensometer with a 12-mm strain gage length connected to the specimens. The applied strains are visualized in Figure 6 . The test temperature was room temperature in air, and a strain rate of $\dot{\varepsilon}_{\text {eq }}=0.2 \% / \mathrm{s}$ was applied. All the tests were conducted under strain control.

The number of cycles to failure (failure life) was defined as the cycle when the amplitude of the axial stress or the shear stress decreased to three-quarters of the maximum stress recorded. This failure condition had been used previously by the group of present authors; this criterion is effective in evaluating the multiaxial failure lives of wrought Ti-6Al-4V materials [19]. Therefore, this condition was adopted for the AM Ti-6Al-4V material. The number of specimens for each condition was one; nevertheless, the effect of internal defects led to scatter in the results. It was assumed that the distribution of defect sizes had some tendency that enabled the evaluation of the failure lives using only one specimen. 
(a)

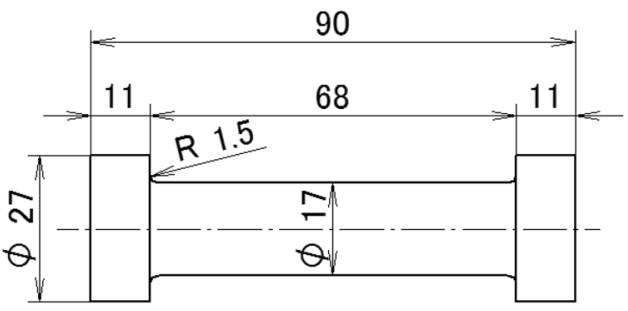

(b)

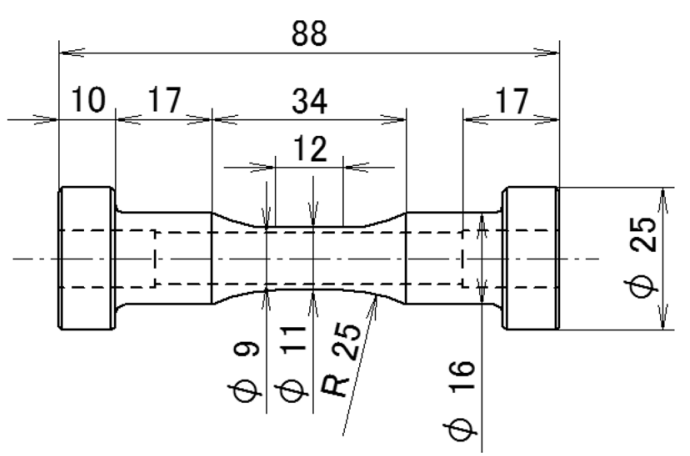

Figure 5 Shape and dimensions of the specimen after (a) L-PBF and $\mathbf{b}$ the machining process

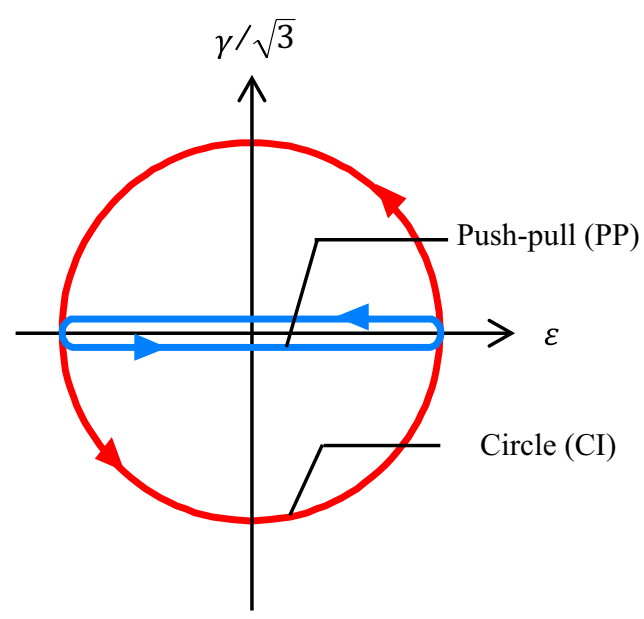

Figure 6 Representation of the PP and Cl strain path used

\section{Experimental Results and Discussion}

\subsection{Fatigue Properties}

Figure 7 shows the test results correlating the von Mises' equivalent strain amplitude, $\Delta \varepsilon_{\mathrm{eq}} / 2$, with the failure life, $N_{\mathrm{f}}$. The horizontal axis is the fatigue life, whereas the vertical axis is the total strain amplitude based on that of von Mises. The results of PP NHT and PP HT are presented using square plots, whereas the results of CI NHT and CI HT are presented using circle plots. The results of the previous study are also presented in Figure 7 . The dashed line shows the factors of the three bands. Figure 8 shows the generated hysteresis loops for $0.5 N_{\mathrm{f}}$ and the maximum stress behavior throughout the tests in each test condition.

The results (Figure 7) of the PP tests show clearly that the data scatter is not drastic and is within the factor of the three bands. Furthermore, there was no difference between the HT and the NHT. The temperature of HT was considered insufficient to remove the residual stresses. However, the data of the PP HT $\left(\Delta \varepsilon_{\text {eq }}=1.3 \%\right)$

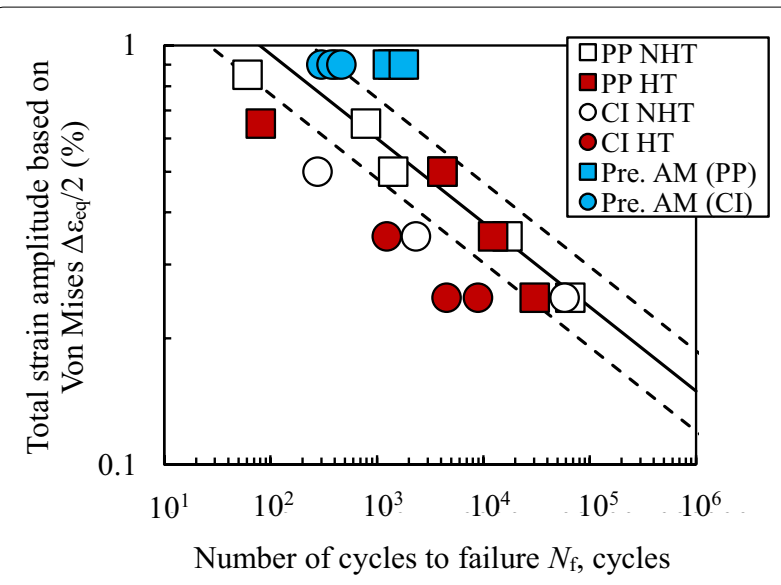

Figure 7 Relationship between the von Mises equivalent strain amplitude $\Delta \varepsilon_{\text {eq }} / 2$ and failure life $N_{f}$

exhibited lower failure lives and were beyond the factor of the three bands. The results of the CI tests are $10 \%$ shorter than those of the PP tests, resulting from the nonproportional multiaxial loading. The results in this study are shorter than previous results, leading to the assumption that the amount of defect is larger in this study. Failure lives at $\Delta \varepsilon_{\text {eq }}=0.5 \%$ have two plots, confirming that the scatter is most prevalent in this range. The failure lives have clear tendencies regardless of the possibility of data scatter originating from the inner defects. This point is discussed further in a later section.

In Figures 8(a), (b), and (e), the hysteresis loops and the maximum stress amplitude at $\Delta \varepsilon_{\mathrm{eq}}=1.3 \%$ are compared. The hysteresis loops indicated approximately the same elastic deformation. The maximum stress amplitude for the NHT remained almost constant. Then, it is likely that the crack initiated in the vicinity of $N_{\mathrm{f}}$ and that the failure occurred rapidly after the initiation of the crack. By contrast, for the HT, the maximum stress amplitude decreased instantly from approximately $0.3 N_{\mathrm{f}}$. Therefore, the crack was considered to have been initiated from 

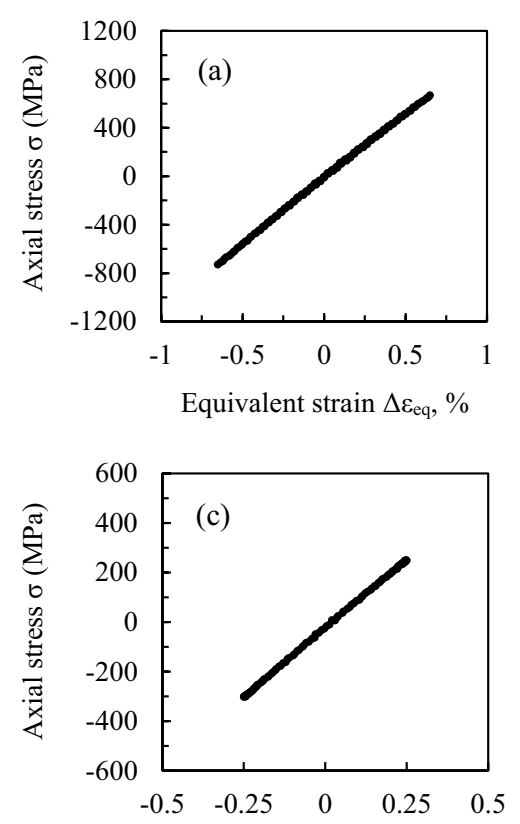

Equivalent strain $\Delta \varepsilon_{\mathrm{eq}}, \%$

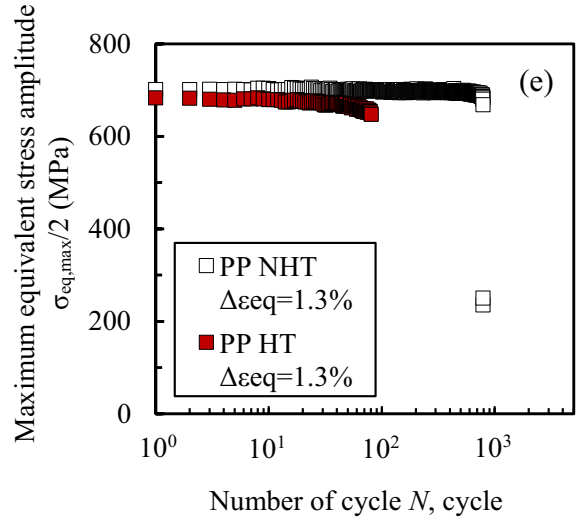

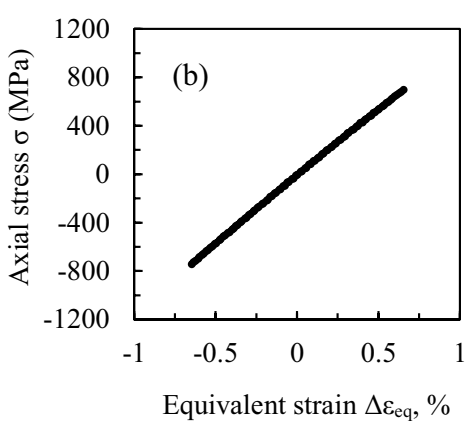
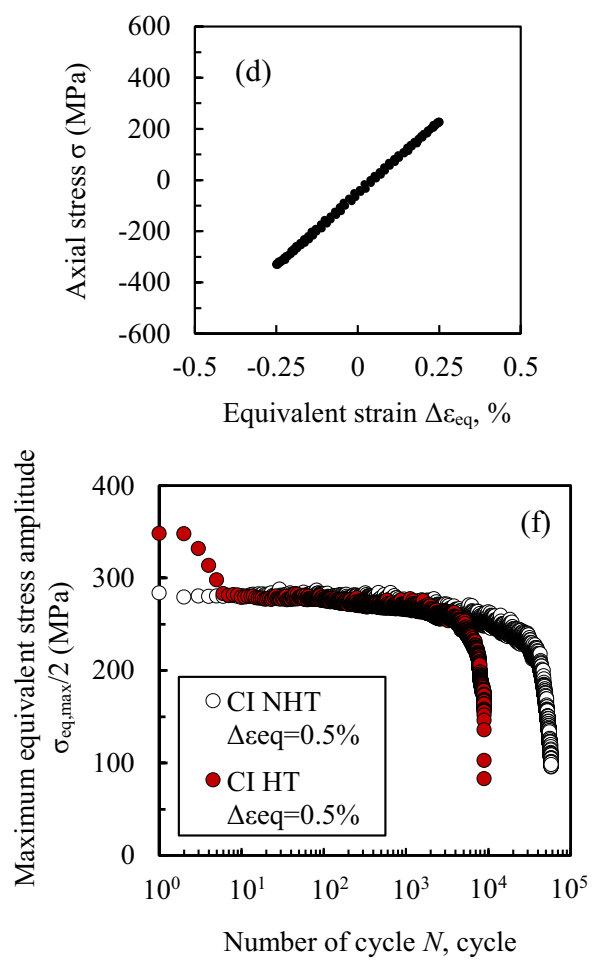

Figure 8 Hysteresis loops obtained at $0.5 \mathrm{~N}_{\mathrm{f}}$ for $\Delta \varepsilon_{\text {eq }}=1.3 \%$ of $\mathbf{a}$ PP HT and $\mathbf{b}$ PP NHT and $\Delta \varepsilon_{\text {eq }}=0.5 \%$ of $\mathbf{c} \mathrm{Cl} H \mathrm{HT}$ and $\mathbf{d} \mathrm{Cl} \mathrm{NHT}$, and maximum stress for $\Delta \varepsilon_{\text {eq }}=1.3 \%$ of $\mathbf{e}$ PP path, maximum stress for $\Delta \varepsilon_{\text {eq }}=0.5 \%$ of $\mathbf{f} \mathrm{Cl}$ path

$0.3 N_{f}$, and after some propagation of the crack, failure occurred.

For the other materials, such as stainless steel and carbon steel, in the case of a low strain level, the failure life was almost the same as that for the PP tests, but this was not clear for this study because of limited data. In Figures $8(\mathrm{c}),(\mathrm{d})$, and (f), the hysteresis loops and the maximum stress amplitude of $\Delta \varepsilon_{\mathrm{eq}}=0.5 \%$ were compared. In the case of a low strain level, the hysteresis loops also exhibited approximately the same elastic deformation. The maximum stress amplitudes for the two pieces of data were similar in deformation behavior. Although the overload was seen in the data for the HT, it is estimated that there was almost no effect because it could have been adjusted in ten cycles. Therefore, why these data show a longer life than the other data remains questionable. The previous test results are also shown in Figure [23]. In the data from the previous study, the failure lives were longer than those in this study. The specimens of the previous study were of the same material (Ti-6Al-4V) but were fabricated with a different manufacturing condition. Based on the abovementioned information, the internal defects were investigated to quantify the sizes of the defects.

\subsection{Internal Defects}

Figure 9 compares the internal defects between the previous study and this study. In the previous study, the 


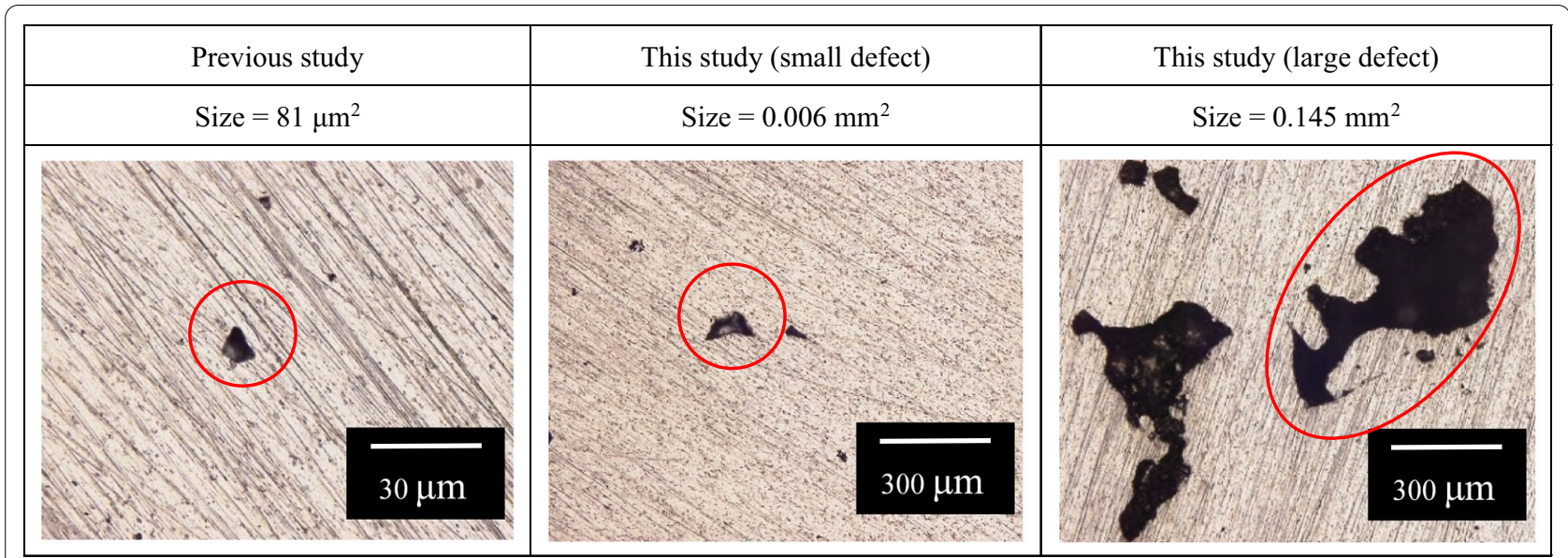

Figure 9 Comparison between the internal defect sizes of theprevious study and this study

Table 1 Relationship between the strain amplitude failure lives and the defect sizes

\begin{tabular}{|c|c|c|c|c|}
\hline $\begin{array}{l}\text { Type of } \\
\text { loading }\end{array}$ & Heat treatment & $\begin{array}{l}\Delta \varepsilon_{\mathrm{eq}} / 2 \\
(\%)\end{array}$ & $\begin{array}{l}N_{\mathrm{f}} \\
\text { Cycles }\end{array}$ & $\begin{array}{l}D_{\text {defect }} \\
(\mu \mathrm{m})\end{array}$ \\
\hline \multirow[t]{10}{*}{ PP } & $\mathrm{NHT}$ & 0.85 & 61 & 161 \\
\hline & & 0.65 & 790 & 77 \\
\hline & & 0.50 & 4152 & 70 \\
\hline & & 0.50 & 1429 & 197 \\
\hline & & 0.35 & 16969 & 9 \\
\hline & & 0.25 & 65771 & 7 \\
\hline & $\mathrm{HT}$ & 0.65 & 81 & 381 \\
\hline & & 0.50 & 4127 & 501 \\
\hline & & 0.35 & 12354 & 167 \\
\hline & & 0.25 & 30504 & 374 \\
\hline \multirow[t]{6}{*}{$\mathrm{Cl}$} & NHT & 0.50 & 278 & 179 \\
\hline & & 0.35 & 2328 & 281 \\
\hline & & 0.25 & 58129 & 105 \\
\hline & HT & 0.35 & 1240 & 591 \\
\hline & & 0.25 & 8945 & 232 \\
\hline & & 0.25 & 4540 & 55 \\
\hline
\end{tabular}

small defects were observed inside, but in this study, the internal defects depended on the observation site. AM components usually have defects inside, and the fatigue strength of the material depends on the size and density of the defect; however, the defect size does not affect the fatigue life above a certain size, as the results of fatigue tests (Figure 7) show a clear correlation regardless of the various defect sizes. Table 1 shows the distribution of defect sizes in the specimens. After fatigue failure of the specimens, grip sections were cut and polished; then, the maximum defect size was measured using an optical microscope. In the Table 1, the total strain amplitudes and the failure lives are also presented. It is clear from the results of the PP NHT that a defect-size range of three times leads to scatter in the failure lives of the factor of three (data of strain amplitude of $0.5 \%$ ). In other words, at most, a three times difference in the defect size does not affect the failure life significantly. As evidence, at a low strain amplitude, the defect size is quite small. It may show that the defect size does not largely govern the failure life.

For the HT materials, the defect size was larger than those of the NHT. In the HT materials, the Vickers hardness was lowered than those of the NHT materials (380.2 versus $404.9 \mathrm{HV}$ of the NHT). Softening due to HT led to larger defect sizes. For the CI tests, a similar trend was seen, confirming that the defect size scatter is directly related to the scatter for fatigue life, although the scatter in failure lives was limited because of the occurrence of fatigue failure at critical defects and probably because of the interaction of defects. This point is discussed further later. As an overview of the defect sizes, the critical size over which failure lives are not affected by defect sizes should be $160 \mu \mathrm{m}$. This is because this size corresponds to the defect at the maximum strain amplitude $(0.85 \%)$ of the NHT and that for a lower strain amplitude $(0.35 \%)$ of the HT in the PP tests.

The defect size nearly corresponds to the average of that of NHT in the CI tests. This confirms that a certain size exists that dominates failure lives. This point is discussed further in a further study. The defect sizes in the previous study were smaller $(9 \mu \mathrm{m})$ than those in this study, leading to longer failure lives.

\subsection{Fracture Surface}

Figure 10 shows pictures of the fracture surface after the fatigue tests, and the observation surface is perpendicular 

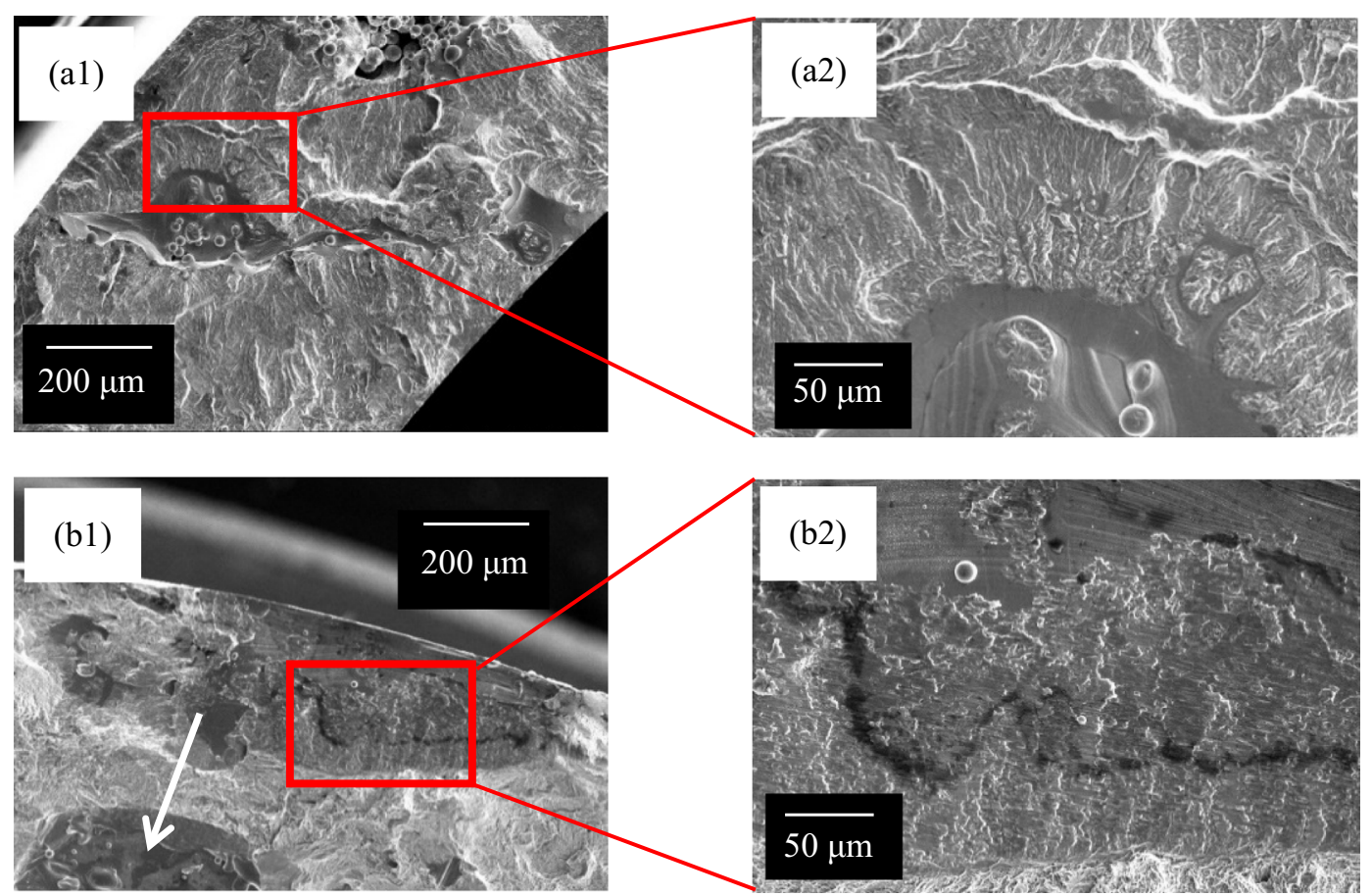

Figure 10 SEM images of the fracture surface: $\mathbf{a}$ push-pull strain path (PP) and $\mathbf{b}$ circle strain path (CI)

to the specimen axis. Dimples were observed around the defects (partly melted defects), and fatigue bands could be identified around them. However, it was difficult to analyze the main crack initiation sites for the specimens in this study. This was probably owing to the interaction of several defects and cracks propagating in a wide range. However, it was clear that the cracks were initiated from the boundaries of the partly melted defects regardless of the strain amplitudes and the strain paths. Further, the stress concentration in the defects caused premature rupture in comparison with the results obtained with the same material [20]. From Figures 10(a2) and (b2), the crack propagation patterns are divided into the first phase (from the crack initiation site to the crack middle site) and the second phase (from the crack middle site to the crack end site) during the test. In the first phase of the test, the propagation path was different depending on the strain paths, and it was possible that high stress existed as evidenced by the rougher fatigue fracture surfaces. In the PP tests, the crack propagated simply, but in the CI tests, it became complicated.

Basically, as a result of the change of the principal direction of stress and strain during the cycle in the $\mathrm{CI}$ tests, the maximum shear stress plane was changed in the cycle. Thus, there is a possibility that the crack was initiated and propagated in many directions. In the second phase of the test, the fatigue fracture surfaces had a similar pattern, and the crack propagation seemed to have been suppressed. It is estimated that a local non-propagating effect took place under the multiaxial stress. Thus, it is possible that the change of the crack propagation pattern in each phase of the test was a characteristic of the AM components with numerous defects, and this was noticeable under nonproportional multiaxial loading.

The white arrow in Figure 10(b1) indicates other crack initiation sites that interact with the upper surface defects. This phenomenon led to the shielding effect of the crack and a temporary cessation in crack propagation. This might have been because the insensitivity of the failure lives depended on the defect sizes of this material. This assumption should be confirmed in further studies. The authors believe that they could evaluate failure lives using one specimen for one condition; however, this point should be clarified in future studies.

In this study, the fatigue strength was found to be absolutely inferior to that of the previous study and of traditionally manufactured components; however, there is a possibility that AM technology could still be used for mechanical structures because the non-propagating effect of the cracks was verified under nonproportional multiaxial loading. 


\section{Conclusions}

(1) The failure lives under PP and CI loading were almost completely unaffected by the HT performed to remove the residual stresses due to an insufficient temperature. In the PP tests, the data scatter was not as drastic, and almost all the data were within the factor of three bands. In the CI tests, although the scattering of the data was also small, the failure life under CI loading was reduced compared with that under PP loading, resulting in a 10\% decrease in failure life.

(2) The small defects were observed inside in the previous study, and the defects were larger in this study. The stress concentration was generated at the boundaries of the defects, and the results of the fatigue test show a clear correlation. Based on the quantification of the maximum defect size, it is speculated that some critical size exists over which the size of the defect does not affect the failure life significantly.

(3) Regardless of the strain amplitude and strain paths, the cracks were initiated from the boundaries of the partially melted defects, indicating that the stress concentration in the defect caused premature rupture compared with the results obtained with the same material.

(4) In the first phase of the test, the propagation path was different because of the strain paths; however, in the second phase of the test, the fatigue fracture surfaces had similar patterns, and propagation of the cracks seemed to have been suppressed.

\section{Acknowledgements}

We would like to thank TRUMPS SISMA SRL for providing the material for the test specimen

\section{Authors' Contributions}

YK was in charge of performing the fatigue tests and writing the manuscript: FO observed the fracture surfaces; TI directed this study. All authors read and approved the final manuscript.

\section{Authors' Information \\ Yuya Kimura, born in 1996, is currently a master graduate at Graduate School of Science \& Engineering, Ritsumeikan University, Japan. \\ Fumio Ogawa, born in 1980, is currently an assistant professor at Fracture and Reliability Research Institute, Graduate School of Engineering, Tohoku University, Japan. He received his Dr. Eng. degree from Waseda University, Japan, in 2014. His research interests include multiaxial fatigue, high-temperature strength, carbon nanotubes, and metal matrix composites. \\ Takamoto Itoh, born in 1965, is currently a professor at the Department of Mechanical Engineering, Ritsumeikan University, Japan. He received his Dr. Eng. degree from Ritsumeikan University, Japan, in 1992. His research interests include multiaxial fatigue and high-temperature strength.}

\section{Funding}

Supported by Japan Society for the Promotion of Science KAKENHI (Grant No. 18H05256).

\section{Competing Interests}

The authors declare no competing financial interests.

\section{Author Details}

${ }^{1}$ Graduate School of Science \& Engineering, Ritsumeikan University, Shiga 5258577, Japan. ${ }^{2}$ Fracture and Reliability Research Institute, Graduate School of Tohoku University, Miyagi 9808579, Japan. ${ }^{3}$ Department of Mechanical Engineering, Ritsumeikan University, Shiga 5258577, Japan.

Received: 30 December 2020 Revised: 5 September 2021 Accepted: 18 October 2021

Published online: 08 November 2021

\section{References}

[1] N Nadammal, T Mishurova, T Fritsch, et al. Critical role of scan strategies on the development of microstructure, texture, and residual stresses during laser powder bed fusion additive manufacuturing. Additive Manufacturing, 2021, 38: 101792.

[2] S C Bodner, LT G van de Vorst, J Zalesak, et al. Inconel-steel multilayers by liquid dispersed metal powder bed fusion: Microstructure, residual stress and property gradients. Additive Manufacturing, 2020, 32: 101027.

[3] M Muhammad, P D Nezhadfar, SThompson, et al. A comparative investigation on the microstructure and mechanical properties of additively manufactured aluminum alloys. International Journal of Fatigue, 2021, 146: 106165.

[4] J Deckers, J Vleugels, J P Kruth. Additive manufacturing of ceramics: A review. Journal of Ceramics Science and Technology, 2014, 5(4): 245-260.

[5] P Mercelis, J Kruth. Residual stresses in selective laser sintering and selective laser melting. Rapid Prototyping Journal, 2006, 12(5): 254-265.

[6] M Shiomi, K Osakada, K Nakamura, et al. Residual stress within metallic model made by selective laser melting process. CIRP Annals, 2004, 53(1): 195-198.

[7] S Leuders, M Thöne, A Riemer, et al. On the mechanical behaviour of titanium alloy TiAl6V4 manufactured by selective laser melting: Fatigue resistance and crack growth performance. International Journal of Fatigue, 2013, 48: 300-307.

[8] B Baufeld, E Brandl, O van der Biest. Wire based additive layer manufacturing: Comparison of microstructure and mechanical properties of Ti-6Al-4V components fabricated by laser-beam deposition and shaped metal deposition. Journal of Materials Processing Technology, 2011, 211(6): 1146-1158.

[9] A Fatemi, R Molaei, S Sharifimehr, et al. Torsional fatigue behavior of wrought and additive manufactured Ti-6Al-4V by powder bed fusion including surface finish effect. International Journal of Fatique, 2017, 100: 347-366.

[10] A Fatemi, R Molaei, S Sharifimehr, et al. Multiaxial fatigue behavior of wrought and additive manufactured Ti-6Al-4V by powder bed fusion including surface finish effect. International Journal of Fatigue, 2017, 99: 187-201.

[11] S Lee, JW Pegues, N Shamsaei. Fatigue behavior and modeling for additive manufactured 304L stainless steel: The effect of surface roughness. International Journal of Fatigue, 2020, 141: 105856.

[12] L Sheridan, J E Gockel, O E Scott-Emuakpor. Stress-defect-life interactions of fatigued additively manufactured alloy 718 . International Journal of Fatique, 2021, 143: 106033.

[13] P Li, D H Warner, A Fatemi, et al. Critical assessment of the fatigue performance of additively manufactured Ti-6Al-4V and perspective for future research. International Journal of Fatigue, 2016, 85: 130-143.

[14] A Sterling, N Shamsaei, B Torries, et al. Fatigue behaviour of additively manufactured Ti-6Al-4V. Procedia Engineering, 2015, 133: 576-589.

[15] K Kanazawa, KJ Miller, M W Brown. Cyclic deformation of $1 \%$ Cr-Mo-V steel under out-of-phase loads. Fatigue and Fracture of Engineering Materials and Structures, 1979, 2(2): 217-228.

[16] E Krempl, H Lu. Comparison of the stress responses of an aluminum alloy tube to proportional and alternate axial and shear strain paths at room temperature. Mechanics of Materials, 1983, 2(3): 183-192.

[17] T Itoh, M Sakane, M Ohnami, et al. Effect of stacking fault energy on cyclic constitutive relation under nonproportional loading. Journal of the Society of Materials Science, Japan, 1992, 41(468): 1361-1367. 
[18] T Itoh, TYang. Material dependence of multiaxial low cycle fatigue lives under nonproportional loading. International Journal of Fatigue, 2011, 33(8): 1025-1031.

[19] M Wu, T Itoh, Y Shimizu, et al. Low cycle fatigue life of Ti-6Al-4V alloy under non-proportional loading. International Journal of Fatigue, 2012, 44: 14-20.

[20] T Nakano. Additive manufacturing for titanium and its alloys. The Japan Institute of Light Metals, 2017, 67(9): 470-480.

[21] J W Pegues, S Shao, N Shamsaei, et al. Fatigue of additive manufactured Ti-6Al-4V, Part I: The effects of powder feed stock, manufacturing, and post process conditions on the resulting microstructure and defects. International Journal of Fatigue, 2020, 132: 105358.
[22] N Molaei, A Fatemi, N Phan. Notched fatigue of additive manufactured metals under uniaxial and multiaxial loadings, Part l: Effects of surface roughness and HIP and comparisons with their wrought alloys. International Journal of Fatigue, 2021, 143: 106003.

[23] S Bressan, F Ogawa, T Itoh, et al. Cyclic plastic behavior of additively manufactured Ti-6Al-4V under uniaxial and multiaxial non-proportional loading. International Journal of Fatigue, 2019, 126: 155-164.

[24] T Nakano, T Ishimoto. Powder-based additive manufacturing for development of tailor-made implants for orthopedic applications. KONA Powder and Particle Journal, 2015, 32: 75-84.

\section{Submit your manuscript to a SpringerOpen ${ }^{\circ}$ journal and benefit from:}

- Convenient online submission

- Rigorous peer review

- Open access: articles freely available online

- High visibility within the field

Retaining the copyright to your article

Submit your next manuscript at $\boldsymbol{\nabla}$ springeropen.com 